\title{
Assessing Yield and Properties of Distillate from Biocrude and Blend after Hydrothermal Liquefaction of Microalgae
}

\author{
EBOIBI, BE \\ Department of Chemical Engineering, Delta State University, Oleh Campus, P.M.B. 22, Oleh, Delta State, Nigeria.
}

Email: blessingeboibi@gmail.com

\begin{abstract}
This paper is on assessing yield and properties of distillate derived from biocrude, and blend stream of biocrude and conventional petroleum. Biocrude was produced from hydrothermal liquefaction of a halophytic microalga Tetraselmis sp. at $350^{\circ} \mathrm{C}, 5 \mathrm{~min}$ with $16 \mathrm{w} / \mathrm{v} \%$ solids content. The resultant biocrude was coprocessed with petroleum using fractional distillation. The result of the study shows that similar yield and quality distillate were obtained from petroleum and blended stream. Distillate fraction obtained from the blend had similar properties such as higher heating values (HHV), $\mathrm{H} / \mathrm{C}$ atomic ratio and elemental composition to those of petroleum crude. The energy density of biocrude-distillate significantly improved from $72.4 \mathrm{MJ} / \mathrm{kg}$ to $86.9 \mathrm{MJ} / \mathrm{kg}$ with about $97 \%$ reduction in oxygen content. Recovery of gasoline fractions with normal boiling point range of $190^{\circ} \mathrm{C}$ to $290^{\circ} \mathrm{C}$ were found higher in petroleum and blend compared to biocrude. This finding is important as coprocessing blend of biocrude and petroleum would address the issues with heteroatoms, which could be of great economic importance. However further studies are necessary on distillate fractions, in order to assure compatibility with petroleum derived fuels.
\end{abstract}

\section{DOI: https://dx.doi.org/10.4314/jasem.v22i6.19}

Copyright: Copyright (C) 2018 Eboibi. This is an open access article distributed under the Creative Commons Attribution License (CCL), which permits unrestricted use, distribution, and reproduction in any medium, provided the original work is properly cited.

Dates: Received: 04 February 2018; Revised: 17 May: 2018; Accepted: 06 June 2018

Keywords: Biocrude; Coprocessing; Microalgae; Hydrothermal liquefaction

Hydrothermal liquefaction (HTL) is a novel promising technology for the complete conversion of whole algae to feedstock upgradable to drop-in fuels. Importantly, it avoids energy-intensive (Cheng et al., 2018; Wagner et al., 2017) normally applied to processes such as transesterification and pyrolysis for biofuels production. HTL of microalgae is carried out at subcritical operating conditions $\left(200^{\circ} \mathrm{C}\right.$ to $\left.374^{\circ} \mathrm{C}\right)$, pressures $5-25 \mathrm{MPa}$, using biomass of $10 \mathrm{wt} \%$ to $20 \mathrm{wt} \%$ solids, with/or without catalyst and water acting as both solvent and catalyst, at vary reaction times (Wang et al., 2018; Fushimi and Umeda, 2016). HTL products include biocrude, solid residue, aqueous phase and gas phase. Research investigation has shown that the primary product, biocrude fall short of conventional refining limit, hence cannot be used directly as transportation fuels (Xu and Savage, 2018). Hence, biocrude requires further upgrading to improve its fuel properties. The aqueous phase can be recycled to algae cultivation pond, while the gas phase contains up to $90 \%$ carbon dioxide and traces of hydrocarbon gases. The solid residue contains nutrient which could be used as substitute to fertilizer, although no literature has been reported on its application. A review of the scientific literature shows that numerous research investigations have been carried out in HTL of microalgae within the last decade. Research investigations on various algae strains (for high lipid and stress resistance and growth rate) (Barreiro et al., 2013; Cheng et al., 2017), different operating reaction conditions (reaction temperature, reaction time, solvents and catalyst) (Xu and Savage, 2015; Eboibi et

Email: blessingeboibi@gmail.com al., 2014a) and several review papers have put together research on HTL of algae-to-biofuel (Vlaskin et al., 2017; Barreiro et al., 2013; Guo et al., 2015). In addition, there have been reports on the life cycle assessments and techno-economic analyses (LCA \& TEA) of HTL-algae-to-biofuels (Pedersen et al., 2018; Delrue et al., 2013; Frank et al., 2012; Liu et al., 2013). Based on these studies, HTL has better energy return on investment (ERoI), lower greenhouse gas (GHG) emission and higher economic potentials compared with the conventional lipid extraction and transesterification processes from microalgae (Biller et al., 2015; Eboibi et al., 2015).

Due to issues on heteroatoms impurity, led to further processing of resultant biocrude by upgrading with catalytic hydro-processing or catalytic and/or noncatalytic hydrothermal in batch/continuous reactors (Bai et al., 2014; Biller et al., 2015; Elliot et al., 2013; Li and Savage, 2013; Roussis et al., 2012). Although, these studies reported improved biocrude yield, enhanced energy density, higher energy recovery in the upgraded biocrude, the heteroatoms, particularly $\mathrm{N}$ content were still higher with at least $2 \mathrm{w} / \mathrm{w} \%$ to $4 \mathrm{w} / \mathrm{w} \%$ compared to petroleum (Eboibi et al., 2015). In addition, the outcomes of these studies have shown that complete replacement of fossil fuels by HTLderived-biofuels is not feasible in the near future (Lavanya et al., 2016). If that being the case, how would HTL-algae biofuels be achieved, could there be any modality for gradual introduction of biocrude to existing refinery? The 'bottom-line' is that further 
studies are needed to be able to achieve drop-in-fuels production from HTL of algae. Like petroleum, HTLbiocrude needs upgrading and refining in order to produce transportation fuels (Liang et al., 2017). One of the potential approach is blending biocrude with petroleum feedstocks (Jiang and Savage, 2017). The few reports of investigations of related studies on blending of pyrolysis derived oils with petroleum shows promising outcomes. Foster et al., (2012) reported coprocessing of pyrolysis oil with standard gas oil to achieve drop-in-fuels. Blending of wood derived oil with diesel fuel were reported by (Nabi et al., (2015). In 2011, De Miguel et al., investigated coprocessing of deoxygenated pyrolysis oils with straight runs gas oil. Generally, the outcomes of these previous reports are promising; considering that similar yields were obtained for blended feeds and pure petroleum. The blends have insignificant effects in engine performance. These studies shows promising result, hence it would be of interest to elucidate yield and characteristics of products obtained from blending of HTL-derived biocrude with petroleum. Therefore the main aim of this reported study is on the feasibility of blending HTL-algal-biocrude with petroleum, to elucidate the energy density and distribution of heteroatoms in distillate products.

\section{MATERIALS AND METHODS}

Feedstock: A halophytic microalga Tetraslmis sp. was used in this present study. The algal was cultured and harvested from open raceway ponds owned and operated by Muradel Pty Limited, in Karatha, Australia. After harvesting and dewatering, the algal biomass was stored at $-8^{\circ} \mathrm{C}$. Freeze-dried biomass (at $48^{\circ} \mathrm{C}$ and pressure $0.133 \mathrm{mBar}$ using $18 \mathrm{~L}$ Labcono FreeZone drier) were transported to India for the studies. HTL and fractionating experimental studies were performed at Biotechnology Division, Aban Infrastructure Pvt. Limited, Chennai, India.

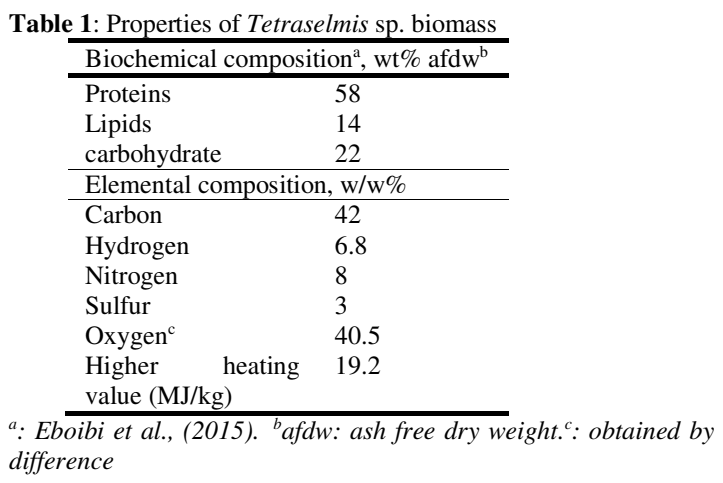

The microalga biochemical composition: protein, lipids and carbohydrate were determined according the methods of Lowry et al., (1951); Folch et al., (1956) and Dubois et al., (1956), respectively. The algal biomass properties (biochemical and elemental composition) are presented in Table 1. The conventional petroleum was obtained from WRPC and use as received.

Hydrothermal liquefaction: HTL were carried out using a custom built $1 \mathrm{~L}$ high pressure-temperature batch reactor with an inbuilt magnetic stirrer. HTL of Tetraselmis sp. was performed at $350^{\circ} \mathrm{C}, 5 \mathrm{~min}$ with $\sim 16 \mathrm{w} / \mathrm{v} \%$ solids loading. Heating of the reactor was provided by an inbuilt electrical heater. The reactor set-up is shown in Fig. 1. The reactor was loaded with $360 \mathrm{~g}$ algal slurry obtained by mixing $60 \mathrm{~g}$ of algal biomass with $300 \mathrm{~g}$ of deionised water. Then the reactor was sealed and heated to $350^{\circ} \mathrm{C}$ reaction temperature using an electrical heater. This temperature was maintained $\left( \pm 4^{\circ} \mathrm{C}\right)$ for 5 min reaction time. During liquefaction the reactant was stirred continuously at 300rpm for homogeneous reaction. The reaction time was set after attaining $350^{\circ} \mathrm{C}$, and stopped after completing $5 \mathrm{~min}$. After complete reaction, the reactor was cooled to room temperature, followed with product separation and recovery.

Product separation and recovery: After cooling the produced gas were vented via gas relief valves. Then the reactor content referred to as product mixture were transferred to a separating funnel, and subsequently diluted with equal volumes of dichloromethane to the amount of product mixture. About $50 \mathrm{ml}$ each of water and dichloromethane were used to rinse the magnetic stirrer and reactor walls. The resultant rinse solution were transferred to the separating funnel containing the rest product mixture. This was followed by manually agitating the separating funnel for about $5 \mathrm{~min}$, in order to improve extraction. Then the separating funnel was allowed to sit for up to $12 \mathrm{hr}$ for phase separation, which led to formation of three phases. An upper phase referred to as aqueous phase; middle layer the biocrude phase containing DCM; and bottom phase, the solid residue fraction. These phases were decanted to separate beakers. The aqueous phase and residue fractions were again washed 2 to 3 times with $100 \mathrm{ml}$ DCM in order to extract residual biocrude. The resultant DCM fractions were added to the biocrude phase containing DCM. The combined biocrude phase were subjected to $40^{\circ} \mathrm{C}$ to evaporate DCM and water, the remnant defined as biocrude (Sheng et al., 2018). The aqueous and residue were quantified after drying at $100^{\circ} \mathrm{C}$ in accordance to (Eboibi et al., 2014a; Yang et al., 2017). 
Fractional distillation of petroleum, produced biocrude and the blend were conducted in accordance to ASTM D1160. The blended stream was made up of $10 \%$ of biocrude and $90 \%$ petroleum. Distillation experimental runs on feedstocks to obtain distillate, residue and loss were conducted in triplicate and the average yield reported with less than $5 \%$ error. Similarly triplicate runs were performed for fractional yields at different temperature.
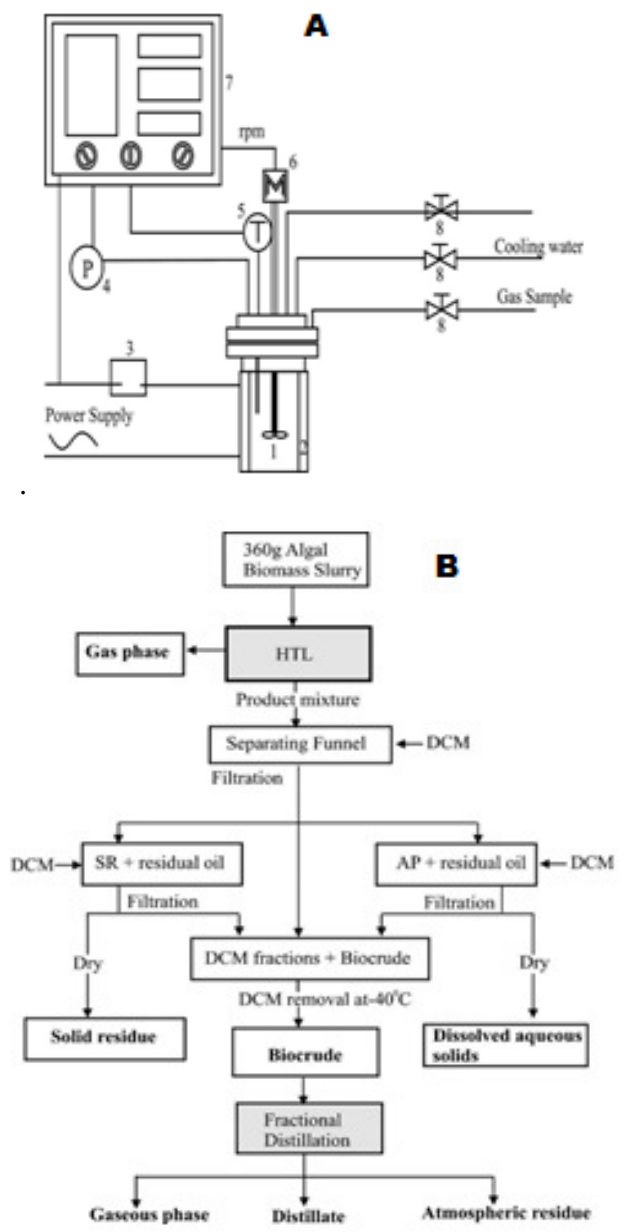

Fig. 1: HTL and Fractional distillation process. (a) HTL reactor set-up. (b) Products recovery and separation procedures

1: Reactor. 2: Electrical heater. 3: Power supply. 4: Pressure sensor. 5: Thermocouple. 6: Magetic stirrer. 7: Contorl box, 8: Valves. HTL: Hydrothermal liquefaction. DCM: Dichloromethane. AP: Aqueous phase. SR: solid residue.

Yields: The yields were determined by relating the mass of products (distillate, residue) to initial mass of feedstock, while loss was determined by difference $(100-$ (distillate + residue $)$ wt $\%)$. Similarly the fractional yields at different temperatures were determined by relating recovered mass to initial weight of feed.

Elemental analysis: The elemental (carbon, hydrogen, nitrogen, and sulfur (CHNS)) composition were determined using VarioEL III elemental analyser system according to ASTM D-5291 and D 3176 methods. The elemental oxygen content was determined by difference $(\mathrm{O}=100-(\mathrm{C}+\mathrm{H}+\mathrm{N}+\mathrm{S}))$ w/w\%). Data obtained for CHNS analyses were used to calculate the higher heating values (HHV) $\mathrm{MJ} / \mathrm{kg}$ using the unified correlation (Eq. (1)) proposed by Channiwala and Parikh, (2002).

$$
\begin{gathered}
H H V\left(\frac{M J}{k g}\right)=0.3491 C+1.1783 H+0.1005 S-0.1034 O \\
-0.0151 N-0.0211 A(1)
\end{gathered}
$$

Where $\mathrm{C}, \mathrm{H}, \mathrm{N}, \mathrm{S}, \mathrm{O}$ and $\mathrm{A}$ are the respective mass of carbon, hydrogen, sulfur, oxygen, nitrogen and ash, on a dry weight basis. Atomic hydrogen-to-carbon, nitrogen-to-carbon, and oxygen-to-carbon ratios were obtained from the CHNSO data and molecular weight of respective elements.

Energy recovery and specie mass balance: Energy recovery (ER) is a term used to describe the amount of energy recovered in product from initial feedstock. ER were calculated using Eq. (2) (Biller and Ross, 2011; Jena et al. 2011). Using a similar equation (Eq. 2), the species mass balances were calculated but after replacing the higher heating values of product and feedstocks with the elemental composition of a particular specie (Eboibi et al., 2014b; Neveuz et al., 2014)

$E R=\frac{H H V \text { of product }\left(\frac{M J}{k g}\right) \times \text { Mass of product }(\mathrm{kg})}{H H V \text { of feedstock }\left(\frac{M J}{\mathrm{~kg}}\right) \times \text { Mass of feedstock }(\mathrm{kg})} \times 100 \%$ (2)

Boiling point distribution-Simulated distillation (SimDist): The boiling point distribution of distillates and raw feeds of petroleum, biocrude, and blend were analysed according to ASTM 7169 method, using gas chromatography equipped with a flame ionisation detector (GC-FID). All samples for SimDist were prepared in accordance to the ASTM 2887 method.

\section{RESULTS AND DISCUSSION}

HTL yield: The results of the study shows $65 \mathrm{wt} \%$ biocrude, solid residue of $15 \mathrm{wt} \%, 12 \mathrm{wt} \%$ aqueous phase and $8 \mathrm{wt} \%$ gas phase were derived from algal initial feedstock. The biocrude yield of $65 \mathrm{wt} \%$ was found higher than $14 \mathrm{wt} \%$ lipids of algal biomass, suggesting the importance of HTL when compared to 
conventional transesterification for biofuel production. Transesterification processes normally extract only the algal lipids component which is converted to biofuel. Based on reported data suggests that using HTL higher products recovery are obtained.

FD yield of petroleum, biocrude and blend: The yields obtained following fractional distillation were $70 \mathrm{wt} \%$ for petroleum and $71 \mathrm{wt} \%$ for the blend. However, the distillate yields from biocrude were lower with $\sim 6 \mathrm{wt} \%$ compared with petroleum and blend. In addition, there were insignificant differences in residue yields and loss for petroleum and blend. An atmospheric residue of $15 \mathrm{wt} \%$ and $16 \mathrm{wt} \%$ were obtained for petroleum and blend, respectively. This finding suggests that blending of petroleum and HTL-algal biocrude would have no effects on yields, however further studies on properties of the distillate are necessary.

The residue obtained from the present study were found to be about $5 \mathrm{wt} \%$ to $14 \mathrm{wt} \%$ higher compared to that derived from vacuum distillation in a previous report (Eboibi et al., 2014b), where 10wt\% residue were reported under optimum operating condition. The variation could be due to the fact that fractional distillation being a unit operation is mostly meant for distillation of low boiling compounds. Whereas vacuum distillation which normally follows fractional distillation is meant for processing of heavier molecular weight compounds that failed to distil using fractional distillation. Hence more distillate could be obtained from the residue if channelled to vacuum distillation.

Interestingly, $15 \mathrm{wt} \%$ gas phase (including loss and water) were obtained from raw petroleum, and $13 \mathrm{wt} \%$ for biocrude. This suggests that raw petroleum could contain more gaseous compounds when compared to biocrude. There could be other reasons for this variation in gaseous yields. One of the possible reasons corroborated with the separation processes involved in recovery of biocrude after production. It could be possible some light fractions were evaporated during evaporation of dichloromethane (at $\sim 40^{\circ} \mathrm{C}$ ) from the mixture of biocrude and DCM, as shown in Fig. 1b. Bai et al., (2014) has shown further processing of biocrude leads to an average $\sim 10 \mathrm{wt} \%$ conversion into gas, where they reported gas yield ranging from $7 \mathrm{wt} \%$ to $14 \mathrm{wt} \%$. The presence of methane, ethane and ammonia has been reported as gaseous compounds following treatment of biocrude. As expected biocrude led to higher residue of $24 \mathrm{wt} \%$ compared to $15 \mathrm{wt} \%$ for petroleum and $\sim 16 \mathrm{wt} \%$ for the blend, which could be due to higher salt content and heavier molecular weight fractions. Such residue fractions could be further process for other useful products, as practiced in conventional refinery. The biocrude used in the present study was produced from a marine halophytic Tetraselmis sp. algal, known to contain salt (Eboibi et al., 2015).

Comparing with previous research, the yields of distillate obtained in this present study were found to be within the range of previous studies investigating processing of biocrude to drop-in fuels. Sarman and Konwer, (2005) reported 89wt\% distillate yield from blending biocrude with petroleum, and $79 \mathrm{wt} \%$ from biocrude following distillation. De Miguel et al., (2011) reported that similar yields were achieved for pure petroleum and blended feed. However, it was found that the residue (16wt\%) obtained in this present study were lower, except for biocrude residue compared to $22 \mathrm{wt} \%$ for marine algal HTL-biocrude blend with petroleum and $24 \mathrm{wt} \%$ for freshwater algal biocrude blend with petroleum (Lavnaya et al., 2016). A residue of $61 \mathrm{wt} \%$ for Maya crude, $57 \mathrm{wt} \%$ for Arab heavy crude and $23.6 \mathrm{wt} \%$ for Narimanam crude was reported. The wide differences in atmospheric residue yields could be mostly due to variations in operating conditions and type of crude/biocrude. As there are light, heavy crude, while others are paraffinic and aromatic; having varying characteristics and geographic origin dependent. In addition, it was observed that the distillate were more viscous and wax formation were noticed in the condenser at higher boiling points. Wax were higher during distillation of biocrude compared to petroleum and blend, which could be due to fatty acids compounds of the original feedstock. The wax build up could be reduced with an increase in temperature, reduction in or temporary stoppage of cooling water (Jensen and Rasmussen, 2014). Furthermore, one of the important terms in conventional refining is the distillation profile, which is one of the focus of analytical result of FD.

- Petroleum abiocrude GBlend ( $10 \%$ Biocrude $+90 \%$ Petroleum)

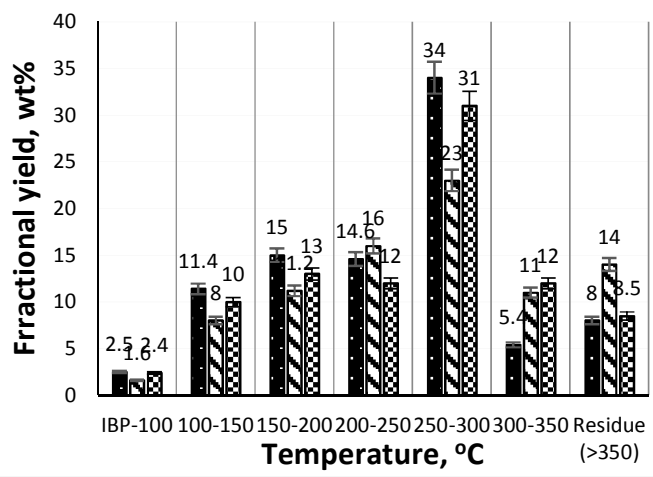

Fig. 2: Fractional distillate yield of petroleum, biocrude and blend obtained at different temperature 
The profile describes the mass fraction and/or volume distilled at specific boiling temperature range. In fact it is the function of the boiling point distribution in terms of temperature. The distillate fractional yields derived from petroleum, biocrude and blend at different temperature is shown in Fig. 2. As illustrated in Fig. 2 the distillates were collected at $\mathrm{IBP}-100^{\circ} \mathrm{C}$, $100-150^{\circ} \mathrm{C}, 150-200^{\circ} \mathrm{C}, 200-250^{\circ} \mathrm{C}, 250-300^{\circ} \mathrm{C}$, and $300-350^{\circ} \mathrm{C}$ with $>350^{\circ} \mathrm{C}$ for residue. There were no much differences in fractional yields for petroleum and the blend at different distillate temperatures.

At lower temperature (IBP- $\left.100^{\circ} \mathrm{C}\right)$, similar yields were obtained for blend and petroleum, higher compared to biocrude. As mentioned previously, the blend and petroleum contained more gaseous product compared to biocrude. All the feedstocks seems to follow similar trends in fractional yields except at $200-250^{\circ} \mathrm{C}$ and $>350^{\circ} \mathrm{C}$, where biocrude had higher yields. This reaffirms that biocrude had higher heavier molecular compounds that could not cracked at lower operating temperature, hence the higher residue fraction.

This reported study has shown that blending of biocrude with petroleum had no significant effects on yields. Importantly, the blend and petroleum had similar residual fractional yield of $8 \mathrm{wt} \%$ and $8.5 \mathrm{wt} \%$, respectively. This is a valuable information for both the refiner and biocrude producer, as blending could address the issue of fossil crisis in the future. One of the viewpoint of biocrude producer is that, the major advantage of blending or coprocessing is reduction in investment costs relating to refining. Due to varying composition of biomass, a potential biorefinery requires several processing units, in order to produce specific liquid transportation fuels. Thus blending biocrude with petroleum seems to be an option for production of drop-in fuels.

Elemental composition of raw feedstock and distillates of petroleum, biocrude and blend: The elemental composition of feedstock and distillates from petroleum, biocrude and blend is presented in Fig. 3. Generally, there were no significant variations in the elemental composition of the distillates and the raw feedstocks for petroleum and the blend, where differences exist, it is only very little. The carbon content for raw petroleum was $85 \mathrm{wt} \%$, with numerical increased to $89 \mathrm{wt} \%$ for its distillate. For the blend, the carbon content increased from $84 \mathrm{wt} \%$ (for raw blend) to $87 \mathrm{wt} \%$ following distillation. This finding suggests that the quality of petroleum and biocrude blend could still be maintained, having found to have similar carbon content with raw petroleum. Moreover, the mild increased observed between raw petroleum and its distillate, suggest the necessity of upgrading for improved fuel properties. For biocrude, there were significant variations for raw biocrude and its distillates, as the carbon content increased from $72.4 \mathrm{w} / \mathrm{w} \%$ to $86.9 \mathrm{w} / \mathrm{w} \%$.

Currently, there are no reported research studies on the distribution of carbon of distillates obtained from FD of HTL-algal- biocrude and blends with petroleum. Though in a related study, Eboibi et al., (2014) reported an increase in carbon content of $68.5 \mathrm{wt} \%$ to $85.2 \mathrm{wt} \%$ and $70.5 \mathrm{wt} \%$ to $85.7 \mathrm{wt} \%$ for vacuum distilled biocrudes derived from Tetraselmis sp. and Spirulina sp., respectively. Importantly, the $84 \mathrm{wt} \%$ carbon content of blend and $87 \mathrm{wt} \%$ distillate was found to be within range of most raw petroleum and upgraded HTL-biocrudes. For example Biller et al., (2015) reported $79 \%$ to $85 \%$ carbon content for upgraded biocrude oils. Speight, (1999) reported that the carbon content of different petroleum are in the range of $83 \mathrm{wt} \%$ to $87 \mathrm{wt} \%$. Suggesting that blending of HTL-biocrude with petroleum would have no negative effects on the carbon content.

Furthermore, the hydrogen content of all distillates obtained from petroleum, biocrude and the blend numerically decreased with $0.5 \mathrm{wt} \%$ to $1 \mathrm{wt} \%$. This is not surprising because loss of hydrogen atoms were expected, since hydrogen was not added during the process as practised in large scale. In fact consumption of hydrogen is an issue worth considering for hydroprocessing, even more for cohydroprocessing because hydrogen consumption is expected for complete removal of oxygen presence in the feedstocks (Chen et al., 2013). As a result the decrease in hydrogen content led to reduction/removal of oxygen content with eventual increased in higher heating values of distillate product, which will be discussed later. The nitrogen of the blend reduced from $1.2 \mathrm{w} / \mathrm{w} \%$ (for raw blend) to $0.2 \mathrm{w} / \mathrm{w} \%$ for distillate, biocrude reduced from $4.7 \mathrm{w} / \mathrm{w} \%$ (raw biocrude) to $\sim 1.2 \mathrm{w} / \mathrm{w} \%$ for distillate, while it was $0.4 \mathrm{wt} \%$ (raw petroleum) to $\sim 0.14 \mathrm{w} / \mathrm{w} \%$ for distillate. Accounting for $63 \%$ to $75 \%$ reduction in nitrogen content for distillates when compared with respective raw feedstocks. Chen et al., (2013) reported 55\% (at $360^{\circ} \mathrm{C}$ ) hydrodenitrogenation (HDN) conversion during coprocessing of a blend of canola oil and heavy vacuum gas oil and $95 \%$ conversion at $395^{\circ} \mathrm{C}$. Suggesting HDN conversion is temperature dependent. Moreover, the data obtained for the distillate nitrogen content was found to be within the range for petroleum $(0.1 \mathrm{w} / \mathrm{w} \%$ to $2 \mathrm{w} / \mathrm{w} \%)$ (Speight, 1999). The nitrogen content of biocrude has been one of the important challenges in HTL-microalgae- 
biocrude, and its reduction to comparable fuel standard has led to several investigations (Eboibi et al., 2015; Elliot et al., 2013). Based on the data reported in this present study particularly nitrogen content of biocrude and petroleum blend, suggests blending and coprocessing of biocrude and petroleum could be one of the available options to produce dropin fuels from HTL-algae-biocrude. Nevertheless further investigation on the distillate fuel fractions for other properties is necessary, in order to ensure compatibility with conventional fossil derived fuels.

The sulfur content for blend had $58 \%$ reduction in both distillates derived from petroleum and blend, and 55\% for biocrude distillates. The reduction in sulfur content could be attributed to loss of hydrogen atom producing hydrogen sulphide. Generally the sulfur content in all distillates was found to be within fuel specifications of marine and jet, and considerably below that of petroleum crude. As the average sulfur content in petroleum crude oils employed in United State refineries is above $1.4 \mathrm{wt} \%$ (Jessen and Ramussen, 2014). Hence giving biocrude and/or blending of HTL-algae-biocrude an additional value compared to petroleum.

Furthermore, the oxygen content was found to have maximum reduction in distillates compared to other impurities such as nitrogen and oxygen. There were no significant differences in oxygen content reduction in petroleum and blend distillates. Deoxygenation occurs during decarboxylation and dehydration reactions, where oxygen is removed in the form of $\mathrm{CO}_{2}$ and $\mathrm{H}_{2} \mathrm{~S}$ (Fogassy et al., 2010; Toor et al., 2011). Remarkably, biocrude distillates had $96.8 \mathrm{w} / \mathrm{w} \%$ oxygen content removal, similar to $83 \mathrm{w} / \mathrm{w} \%$ to $96.8 \mathrm{w} / \mathrm{w} \%$ in oxygen reductions in previous report (Eboibi et al.., 2014b). The distillates of petroleum and blend had similar oxygen content of $1.1 \mathrm{w} / \mathrm{w} \%$ and $1.2 \mathrm{w} / \mathrm{w} \%$, respectively, and was $0.4 \mathrm{w} / \mathrm{w} \%$ for both distillates derived from their raw feedstocks. This reduction accounts for $55 \%$ and $66 \%$ for petroleum and blend distillates, respectively. Although, oxygen content reductions were below $100 \%$, the remaining could be in heavier oxygenate compounds. Nevertheless, the data obtained is satisfactory considering relatively mild operating conditions in present study.

Beside heteroatoms content, the energy density also referred to as higher heating value (HHV) is one of the important data to determine the quality of biocrude. Of which this comparison is mostly made with conventional petroleum. Due to the high amount of oxygen removal in the biocrude, the HHV increased from $35.2 \mathrm{MJ} / \mathrm{kg}$ to $40.3 \mathrm{MJ} / \mathrm{kg}$. The HHV of the blend numerically increased from $43.2 \mathrm{MJ} / \mathrm{kg}$ (raw feed) to
$44 \mathrm{MJ} / \mathrm{kg}$ (distillate). Similar trend was observed for petroleum, increasing from $44 \mathrm{MJ} / \mathrm{kg}$ (raw petroleum) to $45 \mathrm{MJ} / \mathrm{kg}$ (distillate). One of the important outcomes of this present study is that there were no substantial differences in quality of the blend when compared with petroleum. Thus, this study has demonstrated that blending of HTL-algal-biocrude had no negative effects on the energy density. Suggesting coprocessing of biocrude with petroleum in existing refineries could be possible in near future. This would be of great economic promise, with significant reduction in carbon footprint compared to petroleum.

The atomic ratios is also an important factor normally considered to access the energy density and quality of fuel. The hydrogen to carbon ratios of distillates product were generally lower compared to that of feedstocks. The $\mathrm{H} / \mathrm{C}$ ratios of the distillates were 1.7 , 1.2 and 1.6 for petroleum, biocrude and blend, respectively. The decrease in $\mathrm{H} / \mathrm{C}$ ratios reaffirms the loss of hydrogen and carbon molecules towards the removal of oxygenates during decarboxylation and deoxygenation reactions. Hydrogen-to-carbon ratio of the blend and petroleum were found to be similar (1.7 for petroleum and 1.6 for the blend). Previous research has reported hydrogen consumption and decrease in $\mathrm{H} / \mathrm{C}$ atomic ratios during upgrading of biocrude (Biller et al., 2015; Li and Savage, 2013; Duan and Savage, 2011). They reported that the decrease could be due to the high operating temperatures. Nevertheless, hydrogen is normally supplied during industrial processing of crude oils, hence the issue of atomic loss would not be a challenge.

Carbon and energy recovery: It is important that majority of energy and carbon are recovered in primary product following distillation. The carbon and energy recovered in the distillate, residue and loss is presented in Fig. 4. As illustrated in Fig. 4, 86\% of the initial carbon was recovered in distillate obtained from the blended stream, similar to $88 \%$ for petroleum. For biocrude $78 \%$ carbon was recovered in its distillate.

There were no much difference in carbon recovered in residues from petroleum $(8 \%)$, biocrude $(12 \%)$ and $10 \%$ for the blend. Higher amount of carbon was however recovered in loss fraction obtained from biocrude (10\%) compared to $4 \%$ for petroleum as well as blend. Similarly, more than $83 \%$ of the feedstock energy were recovered in distillate fractions, as shown in Fig. 4. Although, the energy recovery was not closed, the other remaining amount could have been distributed to the residue and loss fractions. 


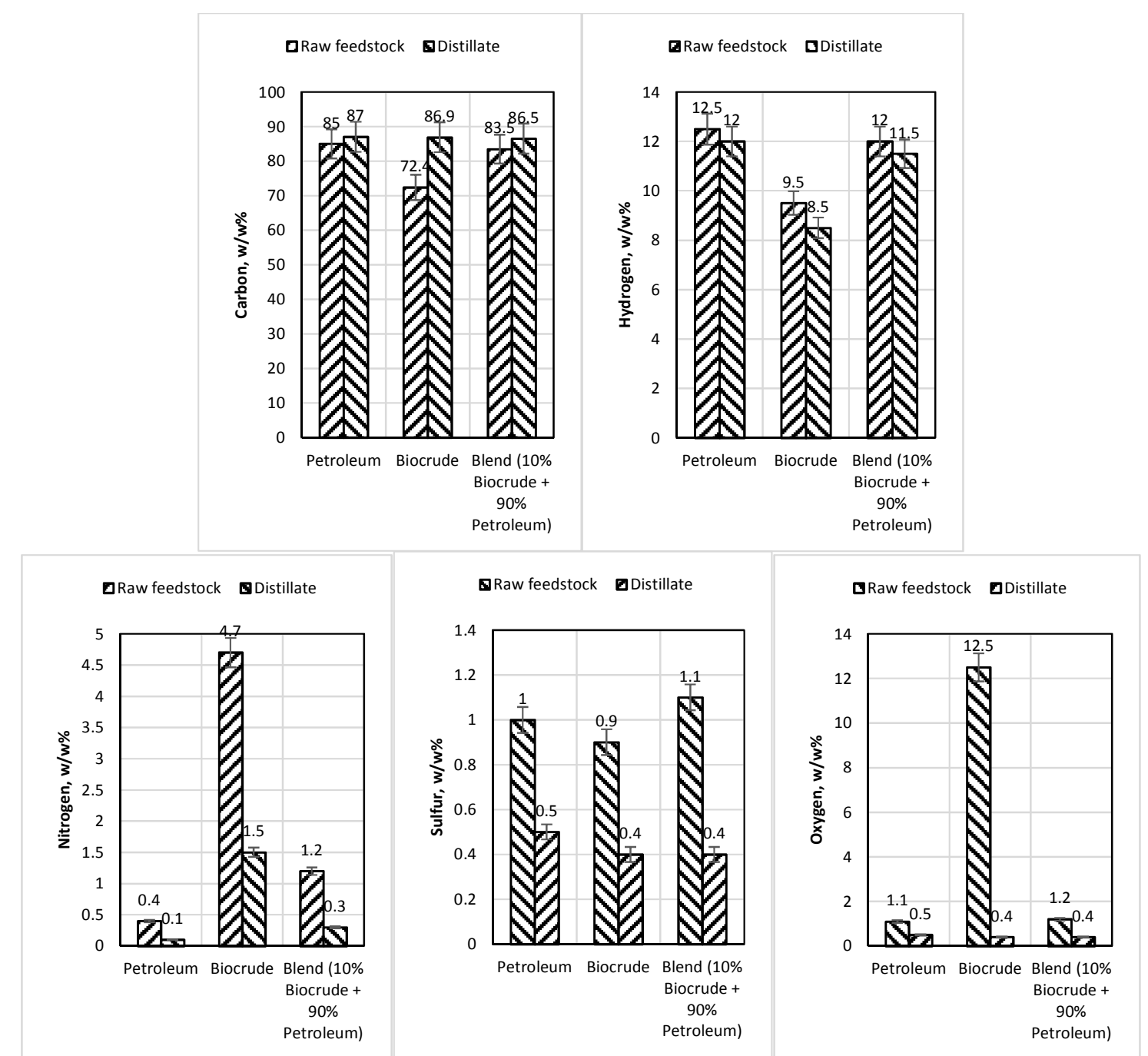

Fig. 3: Elemental composition of raw feedstock and fractional distillate of petroleum, biocrude and blend (of $10 \%$ biocrude and $90 \%$ petroleum)

Conclusively, having similar and larger energy and carbon recovery in distillates obtained for the blend and petroleum, further shows coprocessing of biocrude with petroleum would have insignificant effect on its quality of derived fuels.

Simulated distillation (SimDist) of raw feedstock and distillates: The SimDist data obtained for raw feeds and distillates of petroleum, biocrude and blend is presented in Fig 5. As shown in Fig. 5, there wide differences among the raw feedstock and distillates. The boiling point (bp) fractions of raw feedstocks; petroleum (30\%), biocrude (54\%), and blend (34\%)) were mostly within the range of heavy vacuum gas oil $\left(340-538^{\circ} \mathrm{C}\right)$ (Fig 5a). In contrast the percentage recovery at $340-538^{\circ} \mathrm{C}$ boiling points had an average $50 \%$ decreased for the distillates (Fig. 5b).
However, heavy naptha fractions increased with $38.5 \%, 71.4 \%$ and $42 \%$ for petroleum, biocrude and blend, respectively. This finding corroborate with earlier observation that petroleum comprises of lower bp compounds when compared with biocrude. Generally, distillates recovery were larger in low bp compounds $\left(<340^{\circ} \mathrm{C}\right)$ corresponding to gas oil, kerosene and heavy naphtha fractions. About $68 \%$ of total petroleum, $62 \%$ blend and $44 \%$ biocrude feeds were recovered in heavy naphtha and kerosine fractions, maximum recovered was for kerosine fractions. Moreover, the residues fractions reduced from $14 \%$ to $5 \%$ for petroleum, $16 \%$ to $12 \%$ for biocrude and $14 \%$ to $7 \%$ for blended stream. Similar trends were observed for both petroleum and blended feed. Conclusively, this study has shown that there is no distinct fractional yields and quality between petroleum and blend. 


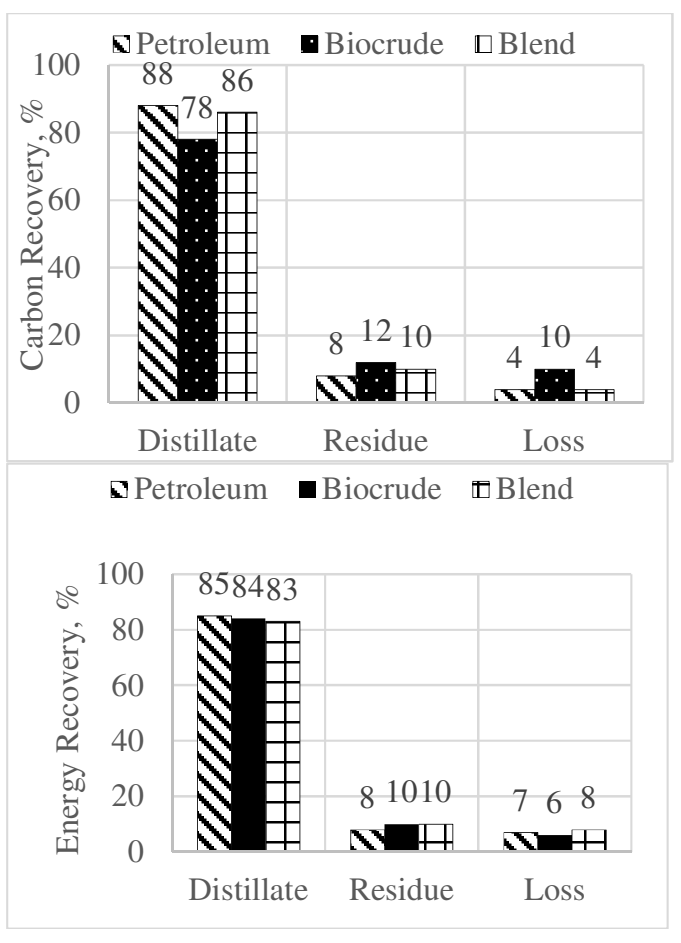

Fig. 4: Carbon and energy recovery after fractional distillation

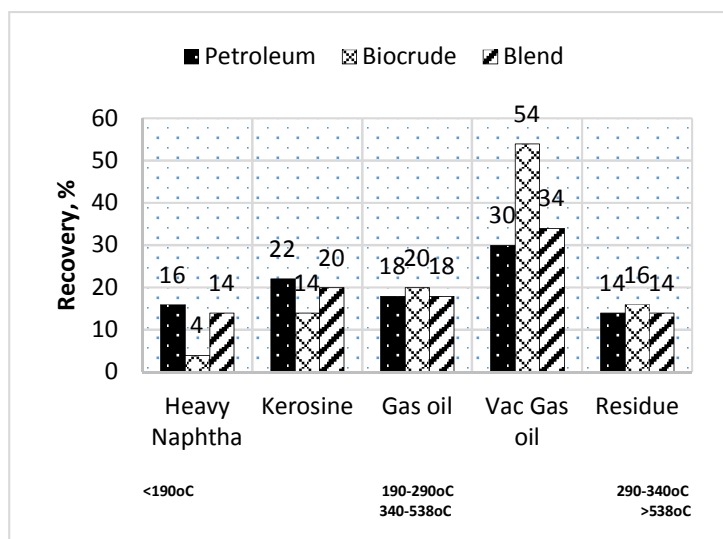

Fig. 5a: Simulated distillation of raw feedstock and distillates of petroleum, biocrude and blend (a) Raw feedstocks (b) distillates

Conclusion: This study has demonstrated the feasibility of blending and coprocessing HTL-algal biocrude with petroleum. Coprocessing of biocrude with petroleum feeds could therefore be an option to address issues on heteroatoms, limiting its usage to production of liquid transportations fuels. Fractional distillation of bicorude significantly improved the quality of biocrude. Nevertheless, in addition to optimal studies, more research investigations are needed, particularly on the distillate fractions to assure compatibility with petroleum derived fuels.

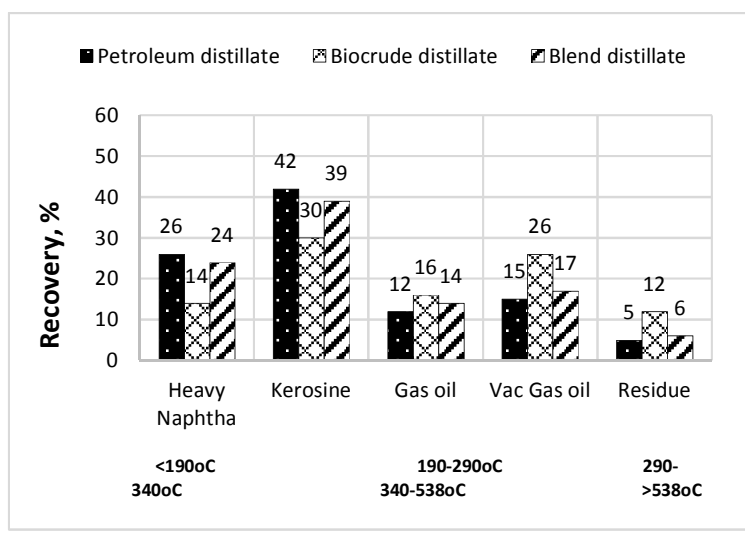

Fig. 5b: Simulated distillation of raw feedstock and distillates of petroleum, biocrude and blend (a) Raw feedstocks (b) distillates

Acknowledgement: This work was supported under Australian Research Council's Linkage Projects Funding Scheme (Project LP100200616), industry partner SQC Pty Ltd and the Australian Biofuels Investment Readiness Program funding agreement No. Q00150. Eboibi is grateful to the support in form of the Postgraduate Research Award provided by Education Trust Fund of the Federal Republic of Nigeria via Delta State University, Nigeria. The author is grateful for the support and technical assistance provided by the Biotechnology Division, Aban Infrastructure Pvt Limited, Chennai, India

\section{REFERENCES}

Agblevor, FA; Mante, O; Clung, R; Oyama, ST (2012). Coprocessing of standard gas oil and bioccrude oil to hydrocarbon fuels. Biomass and Bioenergy, 45, 130-137.

Alba, LG; Torri, C; Samorì, C; van der Spek, J; Fabbri, D; Kersten, SRA; Brilman, DWF (2012). Hydrothermal Treatment (HTT) of Microalgae: Evaluation of the process as conversion method in an algae biorefinery concept. Energy Fuel, 26, 642-657

Bai, X; Duan, P; Xu, Y; Zhang, A; Savage, PE (2014) Hydrothermal catalytic processing of pretreated algal oil: a catalyst screening study. Fuel, 120, 141-9.

Barreiro, DL; Prins, W; Ronsee, F; Brilman, W (2013). Hydrothermal liquefaction of microalgae for biofuel production: State of the art review and future prospects. Biomass and Bioenerg, 53, 113127. 
Biller, P; Sharma, BK; Kunwar, B; Ross, AB (2015). Hydroprocessing of biocrude from continuous hydrothermal liquefaction of microalgae. Fuel 159, 197-205.

Biller, P; Ross, AB. (2012) Hydrothermal processing of algal biomass for the production of biofuels and chemicals. Biofuel., 3, 603,623.

Biller, P; Ross, AB (2011). Potential yields and properties of oil from hydrothermal liquefaction of microalgae with different biochemical content. Bioresource Technol., 102, 215-225.

Channiwala, SA; Parikh, PP (2002). A unified correlation for estimating HHV of solid, liquid and gaseous fuels. Fuel, 81, 1051-1063.

Chen, J; Farooqi, H; Fairbridge, C (2013). Experimental Study on Co-hydroprocessing Canola Oil and Heavy Vacuum Gas Oil Blends. Energy Fuel., 27, 3306-3315.

Chinnasamy, S; Sood, A; Renuka, A; Prasama, R; Ratha, SK; Bhaskar, S; Rengasamy, R; Lewis, DM. (2014). Ecobiological aspects of algae cultivation in wastewaters for recycling of nutrients and biofuel. Biofuel, 5, 141-158

Delrue, F; Li-Beisson, Y; Setier, P-A; Sahut, C; Roubaud, A; Froment, A-K; Peltier, G. (2013). Comparisson of various microalgae liquid biofuel production pathways based on energetic, economic, and environmental criteria. Bioresource Technol., 136, 205-212.

Demirbas, A (2011). Biodiesel production from algae, biofixation of carbondioxide by microalgae: a solution tom pollution problems. Appl Energy, 88, 3541-3547.

Eboibi, BE; Lewis, DM; Ashman, PJ; Chinnasamy, S. (2014a). Effect of operating conditions on yield and quality of biocrude during hydrothermal liquefaction of halophytic Tetraselmis sp. alga. Bioresource Technol., 174, 20-29.

Eboibi, BE; Lewis, DM; Ashman, PJ; Chinnasamy, S. (2014b). Hydrothermal liquefaction of microalage for bocrude production: improving the bicorude properties with vacuum distillation. Bioresource Technol., 174, 212-221.

Eboibi, BE; Lewis, DM; Ashman, PJ; Chinnasamy, S. (2015). Inluence of process conditions on pretreatment of microalgae for protein extration and production of biocrude during hydrothermal liquefaction of pretreated Tetraselmis sp. RSC Adv., 5, 20193.

Elliott, DC; Hart, TR; Schmidt, AJ; Neuenschwander, GG; RotnessL.J; Olarte, WV (2013). Process development for hydrothermal liquefaction of algae feedstocks in a continuous flow reactor. Algal research, 2, 445-54

Fogassy, G; Thegarid, N; Toussaint, G; Van Veen, AC; Schuurman, Y; Mirodatos, C (2010). Biomass derived feedstock co-processing with vacuum gas oil for second-generation fuel production in FCC units. Appl. Cat. B., 96, 476485.

Frank, ED; Elgowainy, A; Han, J;Wang, Z (2012). Life cycle comparison of hydrothermal liquefaction and lipid extraction pathways to renewable diesel from algae. Mitig Adapt Strateg Glob Change. 1-22.

Furimsky, E (2000). Catalytichydrodeoxygenation. Applied Catal. A: General 199(2),147-190.

Furimsky, E (2013). Hydroprocessing challenges in biofuels production. Catalysis Today, 217,13-56.

Fushimi, C; Umeda, A (2016). Comparison of biodiesel production by a supercritical methanol method from microalgae oil using solvent extraction and hydrothermal liquefaction processes. Energy Fuel, 30, 7916-7922.

Guo, Y; Yeh, T; Songa, T; Xua, D; Wang, S. (2015). A review of bio-oil production from hydrothermal liquefaction of algae. Renewable and Sustainable Energy Rev., 48, 776-790.

Jenssen, CU; Rasmussen, KM (2014). Coprocessing of biocrude at petroleum refineries. Masters' thesis submitted to the Deaprtment of Energy Technology, Aalborg Universyt, Denmark.

Liang, S; Wei, K; Passero, ML; Feris, K; McDonald, AG (2017). Hydrothermal Liquefaction of Laboratory Cultivated and Commercial Algal Biomass into Crude Bio-Oil. Environmental Progress \& Sus Energy, DOI 10.1002/ep.

Liu, X; Saydah, B; Eranki, P; Colosi, LM; Mitchell, BG; Rhodes, J; Clarens, AF. (2013). Pilot-scale data provide enhanced estimates of the lifye cycle energy and emissions profile of algae biofuels produced vai hydrothermal liquefaction, Bioresource Technol., 148, 163-177. 
Nabi, MN; Rahman, MM; Islam, MA; Hosain, FM; Brooks, P; Rowlands, WN; Tulloch, J; Ritovski, ZD.; Brown, RJ (2015). Fuel characteristics, engine performance, combustion and exhaust emissions with a new renewable licella biofuel. Energy Convers Manage, 96, 588-598.

Pedersen, TH; Hansen, NH; Pérez, OM; Cabezas, DEV; Rosendahl, LA (2018) Renewable hydrocarbon fuels from hydrothermal liquefaction: A techno-economic analysis. Biofuels, Bioprod. Bioref. 12:213-223.

Roussis, SG; Cranford, R; Sytkovestkiy, N (2012). Thermal treatment of crude algae oils prepared under hydrothermal extraction conditions. Energy Fuel., 26, 5284-5299.

Sarma, AK; Konwer, D (2005). Feasibility studies for conventional refinery distillation with a $(1: 1) \mathrm{w} / \mathrm{w}$ of a biocrude blend with petroleum crude oil, Energy Fuel., 19, 1755-1758.

Sheng, L; Wang, X; Yang, X (2018). Prediction model of biocrude yield and nitrogen heterocyclic compounds analysis by hydrothermal liquefaction of microalgae with model compounds. Bioresource Technol, 247, 14-20.
Speight, G (1999). The chemistry and technology of petroleum, third edition, Marcel Dekker, Inc. New York.

Toor, SS; Rosendahl, L; Rudolf, A (2011) Hydrothermal liquefaction of biomass: A review of subcritical water technologies. Energy, 36, 2318-2342.

Vlaskina, MS; Chernova, NI; Kiseleva, SV; Popel, OS; Zhuk, AZ (2017). Hydrothermal Liquefaction of Microalgae to Produce Biofuels: State of the Art and Future Prospects. Thermal Engineering, 64, 627-636

Wang, W; Xua, Y; Wanga, X; Zhang, B; Tiana, W; Zhang, J (2018). Hydrothermal liquefaction of microalgae over transition metal supported $\mathrm{TiO} 2$ catalyst. Bioresource Technol., 250, 474-480.

Xu, D; Savage, PE (2018) Supercritical water upgrading of water-insoluble and water-soluble biocrudes from hydrothermal liquefaction of Nannochloropsis microalgae. The Journal of Supercritical Fluid, 133, 683-689.

Xu, D; Savage, PE (2015) Effect of reaction time and algae loading on water-soluble and insoluble biocrude fration from hydrothermal liquefaction of algae. Algal research, 12, 60-67. 

